\title{
EFFECT OF FREEZING ON THE ULTRASTRUCTURE OF THE SPERMATOZOON OF SOME DOMESTIC ANIMALS
}

\author{
P. HEALEY* \\ Wellcome Institute of Comparative Physiology, Zoological Society of London
}

(Received 24th Fanuary 1968)

\begin{abstract}
Summary. Spermatozoa of bull, ram, boar, stallion and chinchilla were examined in the electron microscope before and after freezing of samples of semen in liquid nitrogen. The results showed that the ultrastructure of bull spermatozoa was almost identical before and after treatment, but ram and chinchilla spermatozoa showed consistent damage to the outer membrane and acrosome complex. In the ram, damage ranged from slight swelling of the acrosome to total removal of the cytoplasmic regions and most chinchilla spermatozoa were grossly affected. The spermatozoa of boar presented special difficulties at the fixation stage but gross damage to the acrosome was seen. There appeared to be minimal damage to the stallion spermatozoa, although only one sample of this species was examined.
\end{abstract}

\section{INTRODUCTION}

Following the observations on fowl semen by Polge, Smith \& Parkes (1949) of the protective action of glycerol against the deleterious effect of freezing, numerous attempts have been made to preserve the spermatozoa of mammals and light microscope observations on cold damage to spermatozoa are well known (Buttle, Hancock \& Purser, 1965) especially in the large domestic mammals. Among these species, successful preservation, as measured by a high conception rate following artificial insemination, has been obtained in the cow in which the use of frozen semen has become standard agricultural practice.

The techniques currently used for the freezing of bull semen are similar to those described by Polge \& Jakobsen (1959) and Stewart (1961). When applied to the semen of other species they are much less satisfactory and, to date, all modifications have yielded little improvement to their efficacy. Some success has been achieved with the ram and although the motility rate of the spermatozoa after freezing may reach $50 \%$, fertilizing power is low (Emmens, 1962). Niwa, Garrits \& Graham (1962) obtained $70 \%$ motility after thawing epididymal boar spermatozoa frozen in $7 \%$ glycerol, and Bader (1964), using glucose solution, reported a motility of $30 \%$ after thawing in this species, but no conceptions have been recorded in sows inseminated with frozen semen. Zmurin (1961) reported some success with the horse (seven pregnancies in seventeen mares) and later,

* Present address: Huntingdon Research Centre, Huntingdon. 
Kotjagina, Platov \& Rombe (1963) obtained three conceptions in five mares inseminated with frozen semen. The spermatozoa of rodents have proved almost impossible to preserve by freezing (Smith, 1961).

Although these facts have been known for some time, comparatively few attempts have been made to establish the cause of loss of fertilizing capacity after freezing, either by investigating the particular stage in the freezing procedure at which the damage occurs or by morphological examination to determine the nature of the damage and the particular parts of the spermatozoon that are affected. Most workers have used either a motility index or the ratio of live to dead spermatozoa as a light microscope criterion of the success or failure of the freezing and thawing technique. Iype, Abraham \& Bhargava (1963) produced evidence that the acrosome of the bull spermatozoon is removed after storage at $0^{\circ} \mathrm{G}$ and subsequent re-warming, but it may be that the total removal and damage seen with the light microscope is the result of disintegration of the spermatozoon following perhaps even minor damage caused during the freezing process.

The introduction of modern methods of embedding and sectioning for the electron microscope has led to many studies on the normal ultrastructure of the mammalian spermatozoon (see Fawcett, 1958, 1965; Hancock, 1966). The cytoplasmic regions of the head, which the present study mainly concerns, have been examined in cattle (Blom \& Birch-Anderson, 1965), pigs (Nicander \& Bane, 1962), guinea-pigs (Fawcett, 1965), rabbits (Hadek, 1963; Bedford, 1964) and in various species by Nicander \& Bane (1966).

As far as can be determined, no studies have been reported on the ultrastructure of spermatozoa of domestic animals after freezing. The present work was prompted by the failure in this Institute to preserve satisfactorily the semen of some of the rare breeds of British sheep and several exotic species (Sadleir, 1966), and is a preliminary investigation of the damage caused by techniques now in use for the preservation of semen from domestic species.

\section{MATERIALS AND METHODS}

The species used in this study were the bull, ram, boar, stallion and chinchilla. Bull, boar and stallion semen was collected in an artificial vagina and the ram and chinchilla semen by electro-ejaculation. The samples of frozen bull semen were provided by the Cambridge and District Cattle Breeders Association and processed for electron microscopy in parallel with samples of freshly collected semen. In the other species, random samples of each were selected and halved; one half was frozen before fixation and the other was fixed immediately.

Samples for freezing were diluted 1 in 10 with an extender containing $2 \cdot 2$ to $3.6 \%$ sodium citrate and 25 to $50 \%$ egg yolk in distilled water at room temperature and placed at $4^{\circ} \mathrm{C}$. When the temperature of the samples reached about $5^{\circ} \mathrm{C}$ equal volumes of 15 to $20 \%$ glycerol (for bull, ram, boar and stallion) and $15 \%$ dimethyl sulphoxide (for chinchilla) were added; these concentrations of anti-freeze were known to give the highest return of motility after thawing. A period of about $5 \mathrm{hr}$ at $5^{\circ} \mathrm{C}$ was allowed for equilibration and the mixtures were frozen by allowing drops to fall on to solid carbon dioxide 
$\left(-75^{\circ} \mathrm{C}\right)$. The frozen pellets were picked from the block with forceps and then dropped directly into liquid nitrogen $\left(-196^{\circ} \mathrm{G}\right)$. Thawing was effected by placing the tube containing the frozen semen into a beaker of water at room temperature. When temperature equilibrium was reached a sample of the thawed semen was fixed immediately and the remainder used to examine sperm motility. All the samples studied contained motile spermatozoa.

Fixation of fresh and frozen semen was effected by placing one drop of the sample directly into $5 \mathrm{ml}$ of $2 \%$ buffered osmium tetroxide at $\mathrm{pH} 7.4$ (Palade, 1952) for $2 \mathrm{hr}$ at room temperature. It was then centrifuged at $2000 \mathrm{rev} / \mathrm{min}$ for $10 \mathrm{~min}$ and the pellet thus formed rapidly dehydrated in ascending grades of alcohol, cleared in toluene and embedded in Araldite (Giba A.R.L. Ltd, Duxford, Cambridge) epoxide resin (Glauert \& Glauert, 1958). Sections were cut on a Huxley pattern ultramicrotome (Cambridge Instrument Co.), picked up on 200-mesh grids without supporting film and lead-stained by the method of Reynolds (1963). The grids were examined in an A.E.I. EM6B electron microscope, more than 100 different spermatozoa of each sample being studied.

\section{OBSERVATIONS}

Bull (Pl. 1, Figs. 1 and 2)

The ultrastructural appearance of the head of the ejaculated spermatozoon is very similar to that described by Nicander \& Bane (1966) although they do not state whether they are referring to ejaculated or epididymal spermatozoa or both.

In sagittal sections through the heads of two freshly ejaculated bull spermatozoa (Pl. 1, Fig. 1), the outer membrane is seen to be loosely attached in the region of the acrosome and to be in closer association with the head posterior to the acrosome cap termination, as described for the bat (Fawcett \& Ito, 1965). The acrosome extends posteriorly to cover two-thirds of the nucleus; it is quite small and is seen on the ventral side of the head and contains an area of greater density which appears to be a concentration of the normally homogeneous content. The nucleus has a rather mottled appearance and is wedge-shaped in sagittal section, tapering towards the anterior end. The nucleus is separated from the acrosome by a substance of lower density which protrudes into the acrosome. This subacrosomal substance, described by Fawcett \& Ito (1965) and Nicander \& Bane (1966), corresponds to the structure commonly referred to as the perforatorium (Hancock, 1966), but the former term is preferred because of the functional implications of the latter.

Plate 1, Fig. 2 shows the absence of any effect of freezing on the bull spermatozoon. The appearance of the frozen spermatozoon is almost identical, the only detectable difference being that in some spermatozoa the dense area in the acrosome is more pronounced and its edges more sharply defined.

\section{Ram (Pl. 2, Figs. 3, 4 and 5)}

Sagittal sections through the head of an ejaculated ram spermatozoon (Pl. 2, Fig. 3) reveal a structure very similar to that of the bull, the description of the acrosome region and nucleus applying equally to both species. The subacrosomal substance in the ram appears to be slightly more definable than in the bull and the acrosomal dense area is again more indistinct in the unfrozen 
samples. Two spermatozoa from a frozen sample are shown (Pl. 2, Figs. 4 and 5 ) in different stages of disintegration. Initially the acrosome swells with considerable bubbling of the outer surface (arrowed, Pl. 2, Fig. 4), although there appears to be no disruption of the outer membrane at this stage. The dense area in the acrosome has become more prominent, the acrosome content more granular and the nuclear material has lost its mottled appearance and is now homogeneous. A large number of spermatozoa showed almost total loss of the acrosome (Pl. 2, Fig. 5) with remnants of the content adhering to the disintegrating cell membrane. The dense area remains in its original position in relation to the nucleus but is somewhat swollen. Immediately posterior to the acrosome (arrowed, Pl. 2, Fig. 5) the spermatozoon appears normal. Many spermatozoa in the frozen ram samples had outer membranes and acrosome entirely absent, but the subacrosomal substance was always present and a normal structural appearance was presented posterior to the acrosome termination.

Boar (Pl. 3, Figs. 6 and 7)

Fixation of ejaculated boar semen presents special problems which render electron microscopy extremely difficult. When a drop of semen is added to the fixative (osmium tetroxide) it disperses rapidly and the mixture immediately forms a gel which cannot be separated, even by centrifugation. The spermatozoa remain widely dispersed throughout the gel and examination of large numbers is extremely tedious. Plate 3, Fig. 6 is a sagittal section through the head of an untreated spermatozoon and, in general, its appearance is similar to that of the bull and ram. Frozen boar semen does not gel when added to the fixative. Plate 3, Fig. 7 is a section through the head of a frozen spermatozoon showing gross damage to the acrosome. The cytoplasmic regions anterior to the acrosome termination in all the spermatozoa examined were in advanced stages of disintegration.

Stallion (Pl. 3, Figs. 8 and 9 )

No previous electron microscope studies appear to have been published on ejaculated spermatozoa of the stallion although Nicander \& Bane $(1962,1966)$

\section{EXPLANATION OF PLATES 1-4}

$\mathrm{AC}=$ acrosome $; \mathrm{AT}=$ acrosome termination $; \mathrm{DA}=$ dense area within bulb of acrosome; $\mathrm{N}=$ nucleus; $\mathrm{OM}=$ outer membrane of sperm head; sAs = subacrosomal substance; $\mathrm{v}=$ vesicle.

Plate 1. Sagittal sections through the head of two freshly fixed (Fig. 1) and one frozen (Fig. 2) bull spermatozoa, showing absence of structural damage. $\times 45,000$

Plate 2. Sagittal sections through the head of one freshly fixed (Fig. 3) and two frozen (Figs. 4 and 5) ram spermatozoa. The anterior end of the spermatozoon in Fig. 4 is partly obscured by a sperm tail (transverse section) and the three arrows indicate 'bubbling' of the acrosome. $\times 45,000$

Plate 3, Figs. 6 and 7. Sagittal sections of a fresh (Fig. 6) and frozen (Fig. 7) boar spermatozoon. The poor preservation of the nucleus and acrosome in Fig. 6 is due to gel formation on fixation. $\times 45,000$

Plate 3, Figs. 8 and 9. Sagittal sections of sperm head of stallion spermatozoa before (Fig.

8) and after (Fig. 9) freezing, showing absence of structural damage. $\times 30,000$

Plate 4. Sagittal sections through the head of one fresh (Fig. 10) and two frozen (Fig.

11) chinchilla spermatozoa, showing severe damage to the acrosome. $\times 45,000$ 
PLATE 1
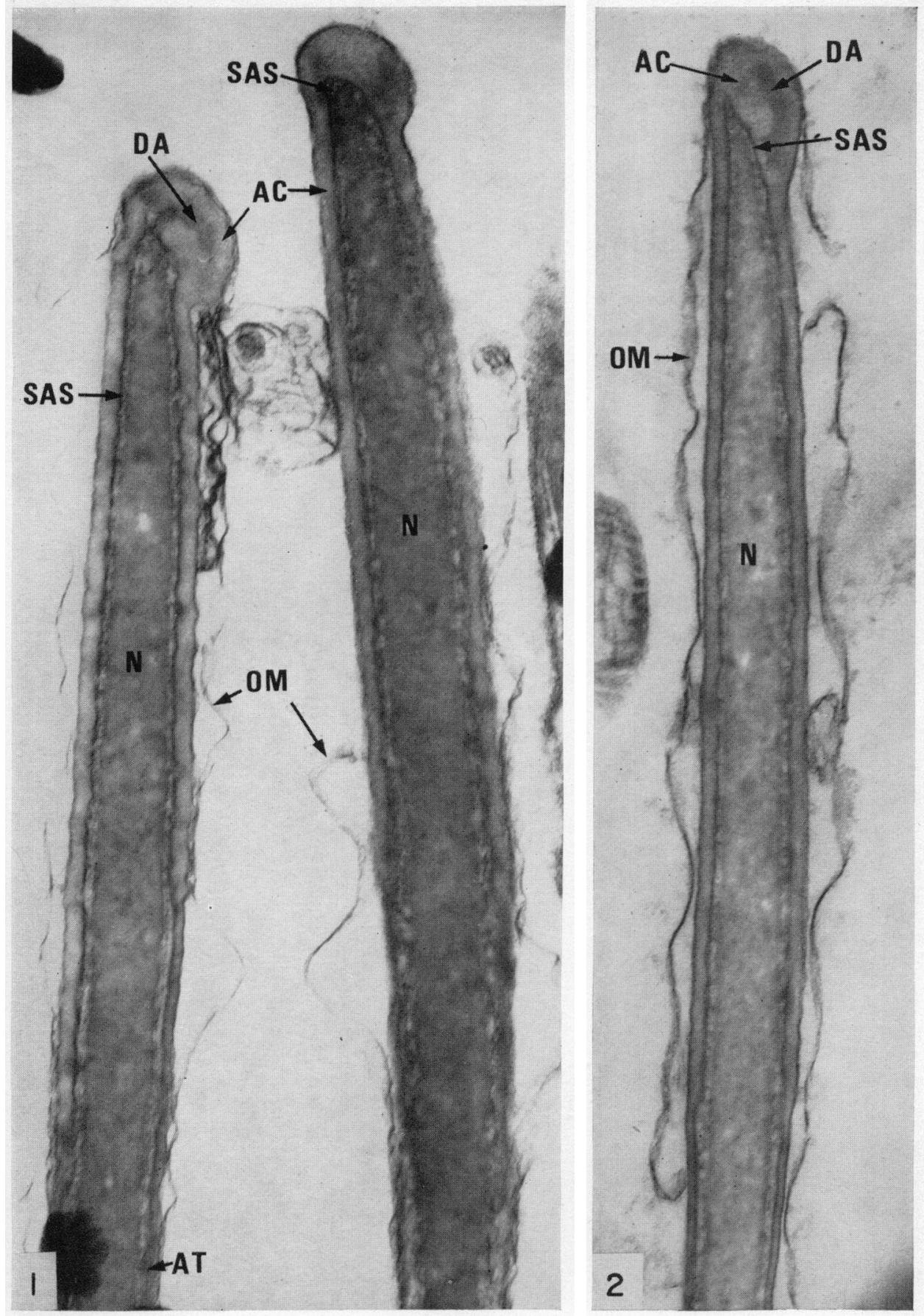

(Facing p. 24) 

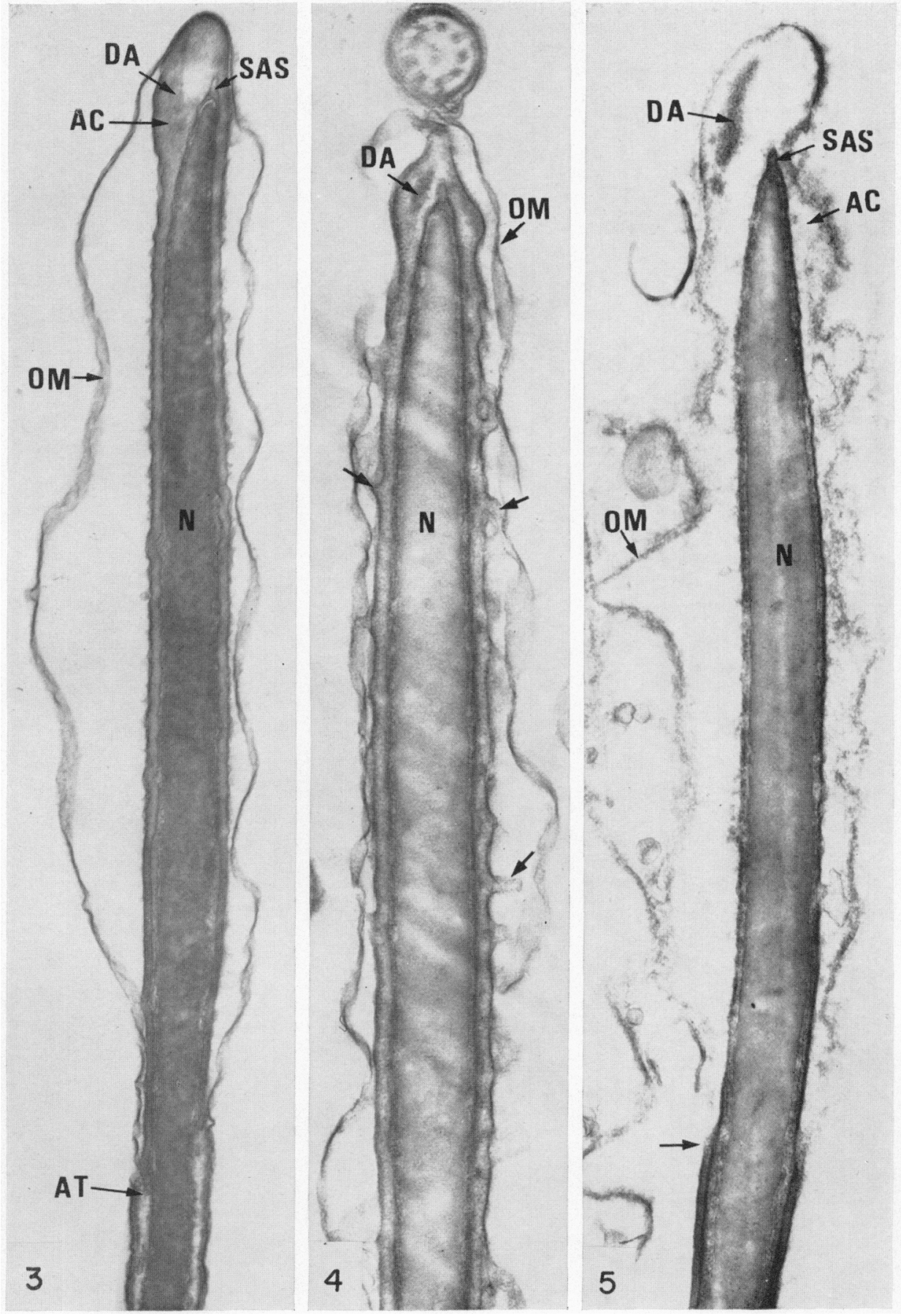
PLATE 3
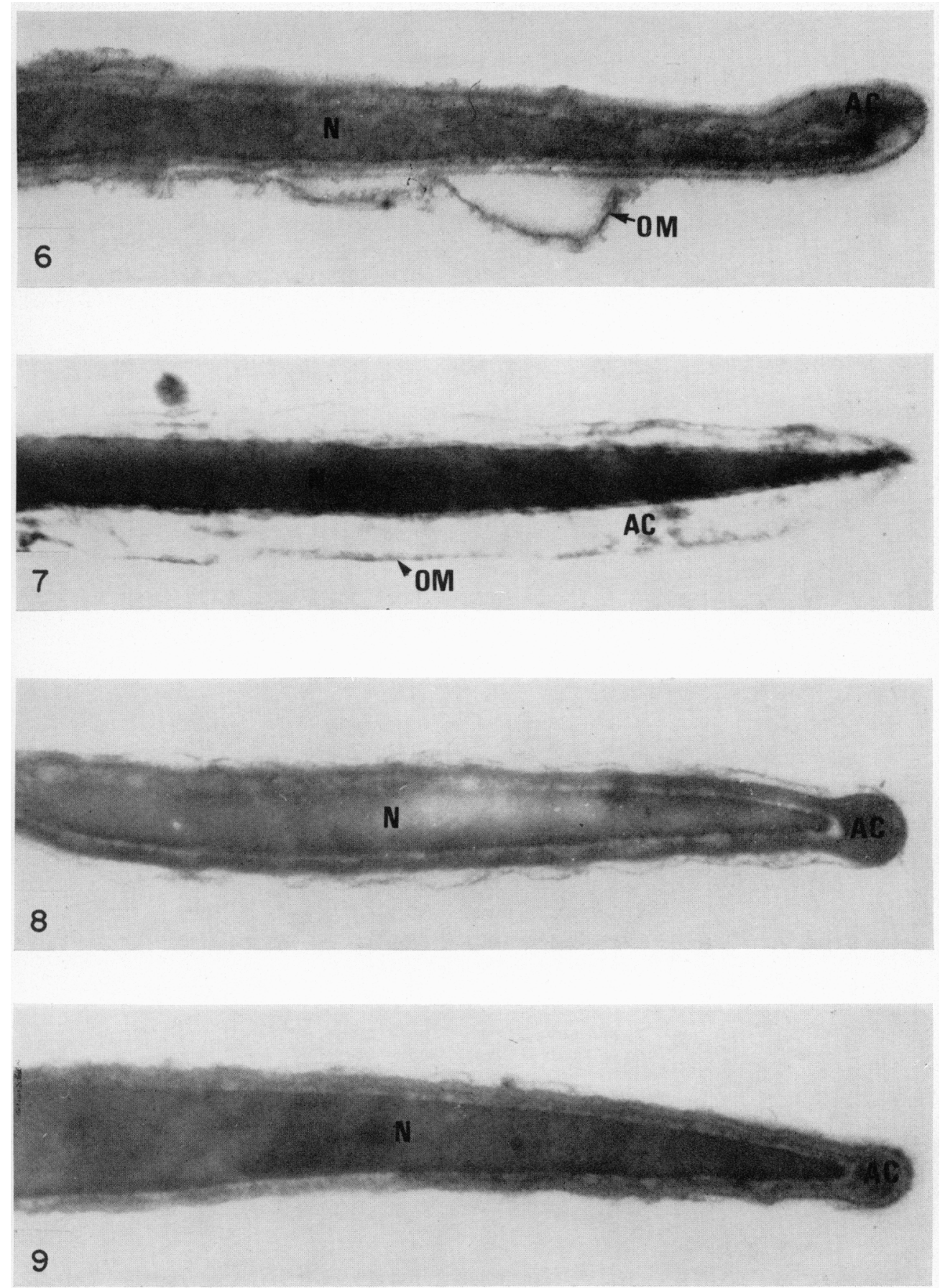
PLAT'E 4
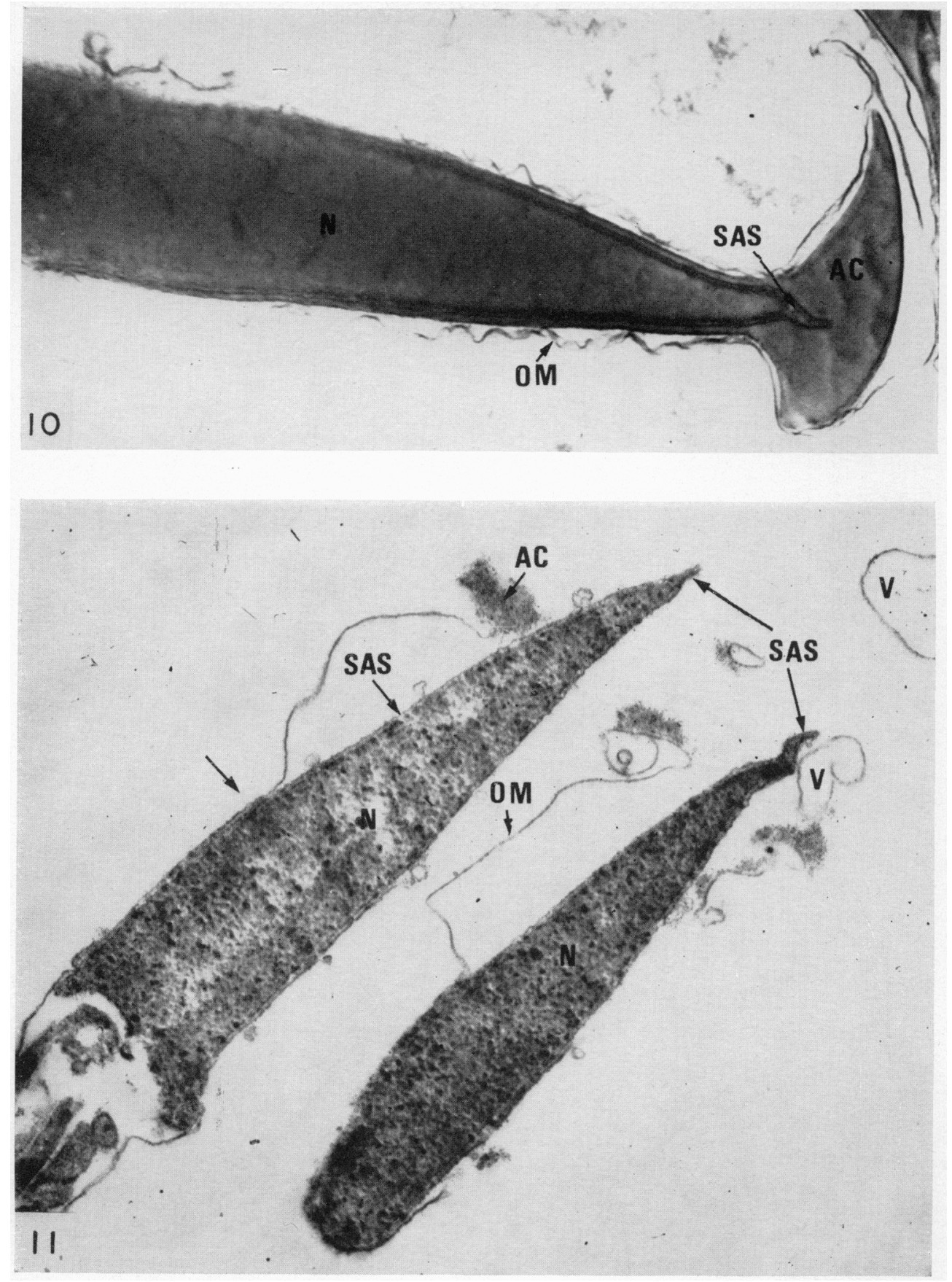

(Facing p. 25) 
have examined the epididymal spermatozoa of this species. Plate 3, Fig. 8 illustrates the general features of the head region of a fresh spermatozoon. The nucleus is rather thin and tapers anteriorly, and the acrosome is small and appears to be symmetrical.

In the one semen sample available for study, freezing seems to have had little, if any, effect on the ultrastructure of the spermatozoa (Pl. 3, Fig. 9). As in the bull, all features seem to be retained.

\section{Chinchilla (Pl. 4, Figs. 10 and 11)}

The ultrastructure of the chinchilla spermatozoon follows the pattern typical of rodent spermatozoa (Fawcett, 1965) in having a very large acrosome which appears very broad and curved in sagittal section (Pl. 4, Fig. 10). The outer membrane readily becomes detached in the region of the acrosome and is convoluted over the whole of this area and at the posterior part of the head, although in this region the membranes appear to be more firmly attached. The nucleus is floccular in appearance although thick sections or dense lead-staining result in a more homogeneous appearance. Subacrosomal substance surrounds the nucleus and protrudes anteriorly into the acrosome.

Plate 4, Fig. 11 shows the heads of two spermatozoa after freezing. The acrosome and outer membranes are almost totally destroyed and remnants of the membranes are seen as vesicles in the surrounding medium. The remaining acrosome content appears granular and the nuclear material has completely coagulated. Posterior to the acrosome termination (arrowed) there is less apparent damage to the cytoplasm.

\section{DISCUSSION}

While recognizing that post mortem changes can occur in spermatozoa (Hancock, 1952), such changes were not considered relevant in the present paper since the object was to detect in living spermatozoa (as determined by motility observed with the light microscope) the time, type and degree of damage consistently occurring during the various treatments. It is obviously significant that the ultrastructure of the frozen bull spermatozoon remains apparently identical to its fresh counterpart and that freezing and thawing procedures have little effect on the fertilizing capacity of such spermatozoa.

In the fresh state, ram, boar and stallion spermatozoa were shown to be very similar in appearance to those of the bull and, as the results of the preservation treatment, drastic effects were produced on the acrosome of the ram and boar. The absence of any detectable effect on the acrosome of stallion spermatozoa is of particular interest in view of the reports mentioned on pp. 21, 22, which indicate that freezing does not altogether destroy their fertilizing capacity. The results so far obtained point to the importance of the acrosome as a structure indispensable to events leading to fertilization. If this structure is an organelle, which stores enzymes for the breakdown of the outer coverings of the egg to permit penetration, as suggested by Austin \& Bishop (1958), it would seem very probable that any damage caused to this part of the sperm-head would interfere with the release of stored substances and thus render the spermatozoa impotent. It was 
apparent throughout the series that the remainder of the structures within the spermatozoa and their motility were unimpaired. No attempt has yet been made to correlate the degree of damage to individual spermatozoa with fertilizing ability, but probably the latter is related to the numbers of undamaged spermatozoa present in an ejaculate rather than to the amount of damage caused to individual spermatozoa.

The reason why spermatozoa of comparable ultrastructure react so differently to similar treatment designed for their preservation may lie in the differences in permeability of the outside membranes and be linked with individual resistance to changes in osmotic pressure to which they are subjected during the freezing process (Lovelock, 1953; Farrant, 1965). Some preliminary work on epididymal ram spermatozoa shows that, unlike earlier light microscope observations, the preservation damage to the spermatozoon is less than that observed for ejaculated samples, even when the account by Saacke \& Almquist (1964) of the degenerative swelling of the bull acrosome after ejaculation is considered.

It was noticeable throughout these experiments that spermatozoa that had been damaged were easier to section and stain than undamaged ones, indicating that the outer membrane and acrosome complex act as a barrier to penetration of such viscous fluids as Araldite. Some work has been started on the effects of various salt solutions on the ultrastructure of the spermatozoon head and it may be that the more delicate spermatozoa will require much greater control of the pressures within and surrounding them during the freezing process (Stevermer, First \& Hoekstra, 1964).

It is possible with the light microscope to assess the number of spermatozoa damaged at a particular level, but with the electron microscope the exact degree of damage in a sample can be readily assessed and very early stages of damage can be detected. For example, in the frozen chinchilla sample the motility was over $25 \%$ after thawing but no undamaged spermatozoa were found during the electron microscope examination.

Clearly, more detailed investigation of the ultrastructure of spermatozoa is necessary to determine the cause of different species-reactions to techniques of preservation and, if possible, to detect the stage at which the damage is caused.

\section{ACKNOWLEDGMENTS}

I am very grateful to $\mathrm{Dr}$ I. W. Rowlands for his guidance and advice throughout the work, to Dr L. G. Goodwin for providing facilities for electron microscopy at the Nuffield Institute of Comparative Medicine and to Professor J. L. Hancock for kindly reading and criticizing the manuscript. The co-operation of $\mathrm{Dr}$ H. M. Dott, Mr L. E. A. Rowson and Dr B. J. Weir in providing the samples of semen is also gratefully acknowledged.

\section{REFERENCES}

Austin, C. R. \& Bishop, M. W. H. (1958) Role of the rodent acrosome and perforatorium in fertilisation. Proc. R. Soc. B, 149, 241.

BADER, B. (1964) Versuche zur Tiefgetrierkonservierung von Ebersamen. Vet.-Med. Dissertation, Tierärztl. Hochsch. Hanover. (1965) Anim. Breed. Abstr. 33, No. 1462.

BEDFORD, J. M. (1964) Fine structure of the sperm head in ejaculated and uterine spermatozoa of the rabbit. F. Reprod. Fert. 7, 221. 
Blom, E. \& Birch-Anderson, A. (1965) The ultrastructure of the bull sperm. II. The sperm head. Nord. VetMed. 17, 193.

Buttle, H. R. L., Hancock, J. L. \& Purser, A. F. (1965) Counting dead spermatozoa in frozen semen. Anim. Prod. 7, 59.

Emmens, G. W. (1962) Dilution, transport and storage of ram semen. In: The Artificial Breeding of Sheep in Australia, p. 118. Ed. E. M. Roberts. University of N.S.W., Sydney.

Farrant, J. (1965) Mechanism of cell damage during freezing and thawing and its prevention. Nature, Lond. 205, 1284.

Fawcett, D. W. (1958) The structure of the mammalian spermatozoon. Int. Rev. Cytol. 7, 195.

FAWCETT, D. W. (1965) The anatomy of the mammalian spermatozoon with particular reference to the guinea-pig. Z. Zellforsch. mikrosk. Anat. 67, 279.

Fawcett, D. W. \& Ito, S. (1965) The fine structure of bat spermatozoa. Am. F. Anat. 116, 567.

Glauert, A. M. \& Glauert, R. H. (1958) Araldite as an embedding medium for electron microscopy. 7. biophys. biochem. Cytol. 4, 191.

HADEK, R. (1963) Study on the fine structure of the rabbit sperm head. F. Ultrastruct. Res. 9, 110.

Hancock, J. L. (1952) The morphology of bull spermatozoa. 7. exp. Biol. 29, 445.

Hancock, J. L. (1966) The ultra-structure of mammalian spermatozoa. In: Advances in Reproductive Physiology, Vol. 1, p. 125. Ed. A. McLaren. Logos Press, London.

Iype, P. T., Abraham, K. A. \& Bhargava, P. M. (1963) Further evidence of a positive role of acrosome in the uptake of labelled amino acids by bovine and avian spermatozoa. F. Reprod. Fert. 5, 151.

Kotjagina, V., Platov, E. \& Rombe, S. (1963) The fertility of stallion semen preserved at a temperature of $-78^{\circ}$. Zhivotnovodstvo, 25, 83. (Russ.) Anim. Breed Abstr. 31, No. 2718.

Lovelock, J. E. (1953) The mechanism of the protective action of glycerol against haemolysis by freezing and thawing. Biochim. biophys. Acta, 11, 28.

NicANDER, L. \& BANE, A. (1962) Fine structure of boar spermatozoa. Z. Zellforsch. mikrosk. Anat. 57, 390.

NICANDER, L. \& BANE, A. (1966) Fine structure of the sperm head in some mammals with particular reference to the acrosome and the subacrosomal substance. Z. Zellforsch. mikrosk. Anat. 72, 496.

Niwa, T., Garrits, R. J. \& Graham, E. F. (1962) Deep freezing of boar semen. (Abstract). F. Anim. Sci. 21, 1027.

Palade, G. E. (1952) Study of fixation for electron microscopy. 7. exp. Med. 95, 285.

Polge, C. \& Jakobsen, K. F. (1959) Techniques for freezing boar semen. Vet. Rec. 71, 928.

Polge, C., Smith, A. U. \& Parkes, A. S. (1949) Revival of sperm after vitrification and dehydration at low temperature. Nature, Lond. 164, 666.

Reynolds, E. S. (1963) The use of lead citrate at high $\mathrm{pH}$ as an electron-opaque stain in electron microscopy. 7. Cell Biol. 17, 208.

SAACKE, R. G. \& AlmQUIST, J. O. (1964) Ultra-structure of bovine spermatozoa. I. The head of normal ejaculated sperm. F. Dairy Sci. 115, 143.

SAdLeIR, R. M. F. S. (1966) The preservation of mammalian spermatozoa by freezing. Lab. Pract. 15, 413.

Smrth, A. U. (1961) Biological effects of freezing and supercooling. Edward Arnold, London.

Stevermer, E. J., First, N. L. \& Hoekstra, W. G. (1964) The effect of osmotic pressure on boar spermatozoa. 7. Anim. Sci. 23, 67.

Stewart, D. L. (1961) Observations on the fertility of frozen semen. Proc. IVth Int. Congr. Anim. Reprod., The Hague, p. 975.

ZMURIN, L. M. (1961) [Diluents for stallion semen frozen to $-20^{\circ} \mathrm{C}$.] Trudy. vses, nauchno-issled. Inst. Konev. 23, 95. Anim. Breed. Abstr. 30, 804. 